\title{
Clinical effects of photodynamic therapy as an adjunct to full-mouth ultrasonic scaling and root planing in treatment of chronic periodontitis
}

\author{
Pitchanun Bundidpun ${ }^{1}$, Rungtiwa Srisuwantha ${ }^{2}$, Narongsak Laosrisin ${ }^{2}$ \\ 1: Dentist, Makarak Hospital, Tha Maka, Kanchanaburi, Thailand. \\ 2: Department of Conservative Dentistry and Prosthodontics, Faculty of Dentistry, \\ Srinakharinwirot University, Bangkok, Thailand.
}

\begin{abstract}
Background and aims: Photodynamic therapy (PDT) is a potential strategy to eliminate infection in the specific tissue. It uses lower-power laser to activate a photosensitizing agent. Studies have shown the benefit of PDT in the periodontal treatment. The aim of this study was to evaluate the periodontal changes after applying PDT as an adjunct to one visit full-mouth SRP (scaling and root planing) with subgingival piezoelectric ultrasonic scaler compared with full-mouth SRP alone.

Methods: A split-mouth randomized clinical trial was designed. Twenty patients with moderate to severe chronic periodontitis were treated with subgingival piezoelectric ultrasonic device alone in control group and adjunct treated with PDT in the test group. Probing pocket depth (PD), clinical attachment level (CAL), plaque index (PI), gingival bleeding index (GBI) and gingival inflammation index (GI) were evaluated at baseline, 1 month, 3 and 6 months after treatment. Only sites with PD $\geq 4 \mathrm{~mm}$ at baseline were calculated.

Results: All periodontal parameters were significantly improved in both groups at 1 month, 3 and 6 months after treatment. All parameters in test group were better than that control group, with statistically significant differences of GBI and GI $(\mathrm{P}<0.05)$ at 3 and 6 months after treatment but no statistically significant differences of PD, CAL and PI.

Conclusions: One visit full-mouth ultrasonic SRP seems to have good enough effort for the periodontal status till 6 months. The adjunct treatment of PDT provided positive effect in term of GBI and GI.
\end{abstract}

Key words: Photodynamic therapy $\cdot$ Chronic periodontitis •

Subgingival piezoelectric ultrasonic scaling and root planing

\section{Introduction}

Periodontitis is a chronic inflammation disease involving the supporting structures of the teeth. The main approach to treat periodontitis involves the removal of dental plaque, supragingival and subgingival deposits from the root surface to stop disease progression ${ }^{1)}$. Non-surgical treatment of periodontitis is conventionally used manual scaling and root planing (SRP). Several studies reported non-surgical periodontal therapy showing significant improvements in clinical and microbial parameters ${ }^{2,3,4)}$. In the last years, one visit full-mouth ultrasonic SRP showed

\section{Addressee for Correspondence:}

Rungtiwa Srisuwantha;

Department of Conservative Dentistry and Prosthodontics,

Faculty of Dentistry, Srinakharinwirot University 114

Sukhumvit 23, Bangkok 10110, Thailand.

Tel :+66 26495000. Fax: +66 26641882.

Email:mimdent@yahoo.com as a new non-surgical techniques similar results as hand instruments for removing plaque and calculus. One visit ultrasonic SRP showed superior to hand SRP which produced smoother roots with less root surface damage, less chair side time, and less operator fatigue than did hand SRP ${ }^{5)}$. Because of their instrument width and small insert tips, furcation may be more accessible using ultrasonic than manual scaler. However, there are some limitations of non-surgical periodontal therapy particularly in deep periodontal pocket due to its difficult for SRP, which lead to decreasing in effectiveness of treatment ${ }^{6}$. Therefore, adjunctive treatment such as photodynamic therapy (PDT) has been proposed to eliminate the periodontopathic bacteria and subsequent recolonization.

PDT provides a capability to reduce bacterial load and to eradicate periodontopathic pathogens. It employs

Received date: July 12th, 2017

Accepted date: September 27th, 2017 
a photosensitizer binding to the target bacteria and is activated by light of a suitable wavelength. During the process of changing the energy status of molecules in the photosensitizer, free radical of singlet oxygen is formed, then causing oxidative damage to cell membrane, mitochondria and nuclei of microorganism ${ }^{77}$. Many studies, in vitro, have shown that several periodontal pathogens, such as Porphyromonas gingivalis (P.g), Aggregatibacter actinomycetemcomitans (A.a) and Prevotella intermedia (P.i) are efficiently eliminated by $\mathrm{PDT}^{8,9,10)}$. Furthermore, PDT also reduce toxic of endotoxin and decrease biological activity of periodontal pathogens ${ }^{11}$. In vivo study, a beagle dog model with PDT using a photosensitizer and a $612 \mathrm{~nm}$ diode laser showed to improve signs of inflammation and possibility to suppress P.g ${ }^{12)}$. Komerik N et al. ${ }^{13)}$ demonstrated that a significant reduction in P.g count was detected after the treatment with toluidine blue $O$ in combination with a diode laser in rat with induced periodontitis. In clinical studies, PDT associated with SRP resulted in a statistically significant improvement in the reduction of probing depth, bleeding on probing and gain of clinical attachment level over SRP alone ${ }^{14,15)}$. Chondros $\mathrm{P}$ et al. ${ }^{16)}$ and Christodoulides $\mathrm{N}$ et al. ${ }^{17)}$ reported PDT resulted in higher reduction of bleeding scores but not in additional improvement in pocket depth reduction and gain of clinical attachment. However, Polansky R et al. ${ }^{18)}$ showed PDT (single cycle) was not an effective adjunct to ultrasonic scaling and root planing and there was no additional effect to eradicating bacteria.

Due to conflicting results, the various types of laser and the different techniques of non-surgical periodontal treatment from previous studies, the aim of the present study to evaluate the changes of periodontal clinical parameters after PDT (single session) as an adjunct to one visit full-mouth ultrasonic SRP compared with SRP alone.

\section{Material and methods}

\section{Subject selection}

Twenty patients with generalized moderate to severe chronic periodontitis were selected, they all had been informed the consent to participate in the study. The study protocol was approved by the Institutional ethics commission at Faculty of Dentistry Srinakharinwirot University (No: 13/2557). Each subject provided informed consent after explanation of the protocol, risk and benefits of study. The inclusion criteria involved the following: generalized moderate to severe chronic periodontitis, presence of at least 20 teeth, at least one molar tooth in each quadrant with a minimum of four teeth, at least two teeth and one molar tooth presented with PD > $6 \mathrm{~mm}$ in each quadrant. The exclusion criteria were the following: systemic illnesses (diabetes mellitus, immunosuppressive drug or HIV), pregnancy or lactation, smoking or alcohol- ism, confirmed or suspected allergy to photosensitizer, previously treated chronic periodontitis, and intake of systemic antibiotics in the previous 6 months.

\section{Sample size calculation}

The sample size was calculated considering a mean probing depth reduction of $1 \mathrm{~mm}$ between groups, with a standard deviation of $1 \mathrm{~mm}$. Base on this, 16 subjects were enrolled in this split mouth design study would be enough to provide $80 \%$ power with a $5 \%$ significance level. Accordingly, 20 subjects were to be recruited to compensate for loss during follow up. Size calculation was based on the formula given below.

$$
\begin{gathered}
\mathrm{n}=\frac{2 \sigma^{2}\left(\mathrm{Z}_{\alpha / 2}+\mathrm{Z}_{\beta}\right)^{2}}{\Delta^{2}} \\
\alpha=0.05 ; \mathrm{Z}_{\alpha / 2}=1.96 \\
\beta=0.20(\text { power }=80 \%) ; \mathrm{Z}_{\beta}=0.84 \\
\Delta(\text { delta }))=\overline{\mathrm{x}} 1-\overline{\mathrm{x}} 2)=1 \\
\sigma=\text { Standard deviation }=1
\end{gathered}
$$

\section{Treatment}

The study was performed according to split-mouth design, computerized randomly allocated to the control or the test group (either right or left sides). The control group was administered by SRP alone but the test group was managed by PDT in addition to SRP. All patients were treated full mouth SRP within one visit by piezoelectric ultrasonic scaler (Suprasson ${ }^{\circledR}$ P5 Newtron, Merignac, France) with specific periodontal tips (Perio tip, Merignac, France). At 1 week after SRP, the test group was then randomly allocated on split-mouth design under another blinded examiner for performing PDT according to the manufacturer's protocol. (HELBO ${ }^{\circledR}$ Photodynamic Systems, Senden, Germany). The photosensitizer dye liquid (phenothiazine chloride: HELBO ${ }^{\circledR}$ Blue photosensitizers) was applied with a blunt needle at the bottom at the periodontal pocket, starting from the bottom of the pocket and gently moving coronally to avoid entrapment of air bubbles, then allowed reacting for 1 minute. Later, the pockets were rinsed with distilled water to remove excess liquid. A diode laser unit: wavelength; $660 \mathrm{~nm}$, output

Table 1: Demographic characteristics of subjects and tooth sites in control and test groups

\begin{tabular}{ll}
\hline Parameters & \\
\hline Number of patient enrolled & 20 \\
Gender (male/female) & $7 / 13$ \\
Age (years; mean \pm SD) & $47.25 \pm 8.91$ \\
Teeth per subject (N; mean \pm SD) & $26 \pm 1.64$ \\
Number of control sites & 789 \\
Number of test sites & 839 \\
\hline
\end{tabular}


power; $100 \mathrm{~mW}$, was attached with a fiber optic pocket probe (HELBO ${ }^{\circledR} 3 \mathrm{D}$ pocket probe), curved at angle of $60^{\circ}$. The probe was inserted into the periodontal pockets, and then laser application was performed circumferentially at six sites per tooth (mesiobuccal, midbuccal, distobuccal, mesiolingual, midlingual and distolingual) for 10 seconds in each. Subsequently, supragingival cleaning was performed with a rubber cup and a low abrasive polishing paste. Clinical assessment was measured at 1 month, 3 and 6 months after treatment. During follow-up visits, supragingival cleansing was performed and oral hygiene instruction was reinforced. All patients were recorded clinical data by a blinded examiner.

\section{Clinical parameters}

The periodontal status of each patient was assessed before treatment (baseline) and at 1month, 3 and 6 months follow-up after treatment. The variables recorded were as follow:

1) Plaque index (PI; Turesky modification of Quigly and Hein, 1970)

2) Gingival inflammation index (GI; Loe \& Sillness, 1963)

3) Probing pocket depth (PD)

4) Clinical attachment level (CAL)

PD and CAL were made on six sites: mesiobuccal, midbuccal, distobuccal, mesiolingual, midlingual and distolingual aspects. For probing measurement, a manual periodontal probe (UNC-15, Hu-Friedy, Chicago, USA) was used.

5) Gingival bleeding index (GBI) was assessed simultaneously with probing pocket depth by recording the presence or the absence of bleeding up to $30 \mathrm{~s}$ after probing.

\section{Statistical analysis}

For statistical analysis, only sites with $\mathrm{PD} \geq 4 \mathrm{~mm}$ at baseline were included in the analysis. Normal distribution of the values was assessed with the Shapiro-Wilk test. All data were not normally distributed, then PD, CAL, GI and PI were analyzed with a non-parametric test employing the SPSS ${ }^{\circledR}$ software version 22 . The mean values and standard deviations for PD, CAL, GI and PI were calculated for both treatment groups. GBI was recorded as the percentage of bleeding on probing. The Mann-Whitney test was used for comparison between the treatment groups. The significance of differences within each group at baseline and after treatment (at 1month, 3 and 6 months) were evaluated by the Wilcoxon signed rank test for PD, CAL, GI and PI. GBI were analyzed with the Chi-square test for comparison between the treatment groups, and the McNemar test for comparison between baseline and after treatment. Differences were considered statistically significant when the $P$ value was less than 0.05 .

\section{Results}

The twenty patients (mean age $47.25 \pm 8.91$ years, from 35-70 years, 13 women and 7 men) were included in the study. There were 789 sites in control group and 839 sites in test group (Table 1). All participants completed 6 months evaluation period. No adverse effects were reported by any of them. Clinical parameters were found no significant differences between the test and control group of the participants with regard to the baseline.

\section{PD, CAL}

PD and CAL shows statistically significant differences improve between baseline and 1 month, 3 and 6 months in both groups (Table 2). At 1 month, 3 and 6 months after

Table 2: Probing pocket depth (PD) and clinical attachment level (CAL) at different time intervals of control and test groups

\begin{tabular}{|c|c|c|c|c|c|c|c|}
\hline Parameters & Baseline & 1 month & $\begin{array}{l}\text { Difference } \\
0-1 \text { month }\end{array}$ & 3 months & $\begin{array}{l}\text { Difference } \\
0-3 \text { months }\end{array}$ & 6 months & $\begin{array}{l}\text { Difference } \\
0-6 \text { months }\end{array}$ \\
\hline \multicolumn{8}{|l|}{$\mathrm{PD}(\mathrm{mm})$} \\
\hline Control group & $4.91 \pm 1.02$ & $3.89 \pm 1.15 \mathrm{~A}$ & $1.02 \pm 0.78$ & $3.50 \pm 1.00 \mathrm{~A}$ & $1.41 \pm 0.84$ & $3.02 \pm 0.81 \mathrm{~A}$ & $1.89 \pm 0.92$ \\
\hline Test group & $4.96 \pm 1.11$ & $3.91 \pm 1.11 \mathrm{~A}$ & $1.05 \pm 0.90$ & $3.54 \pm 0.94 \mathrm{~A}$ & $1.42 \pm 0.84$ & $2.97 \pm 0.74 \mathrm{~A}$ & $1.99 \pm 0.89$ \\
\hline$P$-value & 0.16 & 0.62 & & 0.95 & & 0.58 & \\
\hline \multicolumn{8}{|l|}{ CAL $(\mathrm{mm})$} \\
\hline Control group & $5.01 \pm 1.57$ & $4.35 \pm 1.50 \mathrm{~A}$ & $0.66 \pm 1.00$ & $4.17 \pm 1.38 \mathrm{~A}$ & $0.84 \pm 1.00$ & $3.89 \pm 1.33 \mathrm{~A}$ & $1.12 \pm 1.16$ \\
\hline Test group & $5.15 \pm 1.56$ & $4.46+1.49 \mathrm{~A}$ & $0.69 \pm 1.15$ & $4.26 \pm 1.33 \mathrm{~A}$ & $0.89 \pm 1.09$ & $3.99 \pm 1.23 \mathrm{~A}$ & $1.16 \pm 1.16$ \\
\hline$P$-value & 0.09 & 0.09 & & 0.09 & & 0.05 & \\
\hline
\end{tabular}

Different uppercase letters represent intragroup statistically significant difference (Wilcoxon signed ranks test, $P<0.05$ ) 
treatment from initial value the PD decrease $1.02 \pm 0.78$ $\mathrm{mm}, 1.41 \pm 0.84 \mathrm{~mm}$ and $1.89 \pm 0.92 \mathrm{~mm}$, respectively in control group. Also at this time interval the PD decrease $1.05 \pm 1.11 \mathrm{~mm}, 1.42 \pm 0.84 \mathrm{~mm}$ and $1.99 \pm 0.89 \mathrm{~mm}$, respectively in test group. At 1 month, 3 and 6 months after treatment from initial value the CAL gain $0.66 \pm 1.00 \mathrm{~mm}$, $0.84 \pm 1.00 \mathrm{~mm}$ and $1.12 \pm 1.16 \mathrm{~mm}$, respectively in control group. Also at this time interval the CAL gain $0.69 \pm$ $1.15 \mathrm{~mm}, 0.89 \pm 1.09 \mathrm{~mm}$ and $1.16 \pm 1.16 \mathrm{~mm}$, respectively in test group. No statistically significant differences in term of PD and CAL were observed between two groups at any time point (Table 2).

\section{PI, GI}

PI and GI show statistically significant differences reduced between baseline and 1 month, 3 and 6 months in both groups (Table 3). After 6 months, a slight increase in the PI and GI was observed when compared 3 months after treatment. No statistically significant differences in term of PI between the two groups at any time point but GI was statistically significant reduction in the test group at 3 and 6 months after periodontal treatment as compared to control group.

\section{GBI}

GBI shows a statistically significant difference decreased between baseline and 1 month, 3 and 6 months in both groups (Table 4). After 6 months, a slight increase in the GBI was observed when compared 3 months after treatment. As compared to control group, GBI was statistically significant reduction in the test group at 3 and 6 months after treatment. Comparisons the changes of values for GBI from baseline to follow-up at 6 months, the GBI decrease were $43.10 \%$ in control group and $52.20 \%$ in test group.

\section{Number of sites with probing pocket depth (PD) $\geq 4$ and $\geq 5 \mathrm{~mm}$.}

The number with $\mathrm{PD} \geq 4 \mathrm{~mm}$ and $\geq 5 \mathrm{~mm}$ at baseline, 1 month, 3 and 6 months are shown in Table 5. The number of pockets with $\mathrm{PD} \geq 4 \mathrm{~mm}$ and $\geq 5 \mathrm{~mm}$ showed significant reduction between baseline and all three times points in both groups, but there was no significant differences between group at any time. However, at the 6 months follow up, percentage of reduction in number of $\mathrm{PD} \geq 4 \mathrm{~mm}$ and $\geq 5 \mathrm{~mm}$ in test group higher than in control group. Result in test group showed reduction in number of $\mathrm{PD} \geq 4 \mathrm{~mm}$ at $76.52 \%$, which higher than control group which reduced to $75.24 \%$. At 6 months after treatment, test group had remaining number of $\mathrm{PD} \geq 5 \mathrm{~mm}$ at $18.65 \%$, compare to the baseline, which had remaining less than control group at $20.23 \%$.

Table 3: Plaque index (PI) and gingival inflammation index (GI) at different time intervals of control and test groups

\begin{tabular}{lcccc}
\hline Parameters & Baseline & 1 month & 3 months & 6 months \\
\hline PI & & & & $2.15 \pm 1.06 \mathrm{~A}$ \\
Control group & $3.02 \pm 1.08$ & $2.34 \pm 0.96 \mathrm{~A}$ & $1.98 \pm 0.97 \mathrm{~A}$ & $2.06 \pm 1.09 \mathrm{~A}$ \\
Test group & $3.01 \pm 1.07$ & $2.36 \pm 0.97 \mathrm{~A}$ & $2.02 \pm 0.98 \mathrm{~A}$ & 0.20 \\
$P$-value & 0.89 & 0.87 & 0.52 & $1.18 \pm 0.81 \mathrm{Aa}$ \\
GI & & & & $1.14 \pm 0.78 \mathrm{Aa}$ \\
Control group & $1.86 \pm 0.41$ & $1.30 \pm 0.73 \mathrm{~A}$ & $0.98 \pm 0.79 \mathrm{Aa}$ & $1.06 \pm 0.82 \mathrm{Aa}$ \\
Test group & $1.88 \pm 0.40$ & $1.24 \pm 0.70 \mathrm{~A}$ & 0.001 & 0.02 \\
$P$-value & 0.31 & 0.10 &
\end{tabular}

Different uppercase letters represent intragroup statistically significant difference (Wilcoxon signed ranks test, $P<0.05$ )

Different lowercase letters represent inter-group statistically significant difference (Mann-Whitney $\mathrm{U}$ test, $P<0.05$ )

Table 4: Gingival bleeding index (GBI) at different time intervals of control and test groups

\begin{tabular}{|c|c|c|c|c|c|}
\hline GBI (\%) & Baseline & 1 month & 3 months & 6 months & $\begin{array}{l}\text { Difference } \\
\text { 0-6 months }\end{array}$ \\
\hline Control group & 83.60 & $45.20 \mathrm{~A}$ & $38.10 \mathrm{Aa}$ & $40.50 \mathrm{Aa}$ & 43.10 \\
\hline Test group & 85.50 & $42.00 \mathrm{~A}$ & 30.00Aa & 33.30Aa & 52.20 \\
\hline$P$-value & 0.41 & 0.29 & 0.01 & 0.01 & \\
\hline
\end{tabular}

Different uppercase letters represent intragroup statistically significant difference (McNemar Test, $P<0.05$ )

Different lowercase letters represent inter-group statistically significant difference (Chi-square test, $P<0.05$ ) 


\section{Discussion}

Although PDT has been used increasingly in periodontal treatment, it is still partly being discussed controversially. This study showed that the addition application of a single episode of PDT to SRP resulting in significantly higher reduction of GI and GBI than with SRP alone but it did not provided additional positive effect in term of PD and PI reduction and CAL gain.

In this study, it was employed a split-mouth design which had benefit in controlling variable between personal. The photosensitizer, phenothiazine chloride at a concentration $10 \mathrm{mg} / \mathrm{ml}$ had been tested in several in vitro, preclinical and clinical studies with result of no side effects related. It was also approved by Food and Drug Administration (FDA), which was safe to use for treatment in patients ${ }^{19}$. In addition, this study found that none of the patients had side effect from this treatment.

Several studies revealed that the combination of PDT with SRP promoted greater reduction in gingival bleeding compared with SRP alone which may resulted from reduction of pro-inflammatory mediators ${ }^{16,17)}$. Quadri $T$ et al. ${ }^{20)}$ also reported that gingival inflammation, which indicated by a significant decrease gingival crevicular fluid volume was decreased after low-level laser has been use as adjunct therapy in periodontal treatment. Kolbe MF et al. ${ }^{21)}$ demonstrated that only PDT-treated periodontal pocket exhibit increased levels of anti-inflammatory IL- 4 and reduced amounts of pro-inflammatory IL-1 $\beta$ and IL- 6 . In this study, all patients were able to maintain well oral hygiene, finding that both groups had plaque index at similar rate. Thus, the plaque did not effect to differentiate significantly of gingival bleeding and gingival inflammation index. PDT may respond for good effect in reducing gingival inflammation.

The results of this study was in agreement with Chondros $\mathrm{P}$ et al. ${ }^{16)}$ and Christodoulides $\mathrm{N}$ et al. ${ }^{17)}$ which also failed to show significant difference positive effects in terms of PD reduction and CAL gain by PDT as an adjunctive therapy to SRP. It well known that the plaque is a major contributory factor for periodontitis. Full-mouth subgingival debridement with supragingival plaque control in subjects with chronic periodontitis was practically effective in reducing $\mathrm{PD}$ and improving $\mathrm{CAL}^{1-3)}$. In terms of PI, this study showed comparable outcome of PI between the groups at any time point. Thus, the data indicated that PI may affect the result of PD and CAL changes which did not achieve significant improvements between the two groups. For further study, the microbiological evaluation in term of a subgingival bacteria, such as P.gingivalis, will be performed to confirm the effective of this photodynamic treatment on periodontitis.

Conversely, Andersen R et al. ${ }^{14)}$ reported a statistically difference in clinical attachment gain of $0.86 \mathrm{~mm}$ and a reduction in pocket depth of $1.11 \mathrm{~mm}$ for the group treated with SRP combined PDT, and the group treated with SRP alone had a clinical attachment gain of $0.36 \mathrm{~mm}$ and a reduction in pocket depth of $0.74 \mathrm{~mm}$. Similarly, Braun A et al. ${ }^{15)}$ revealed statistically significant reduction in pocket depth and clinical attachment gains after SRP with adjunctive PDT than SRP alone.

During 6 months follow up, the authors found that the test group in group of periodontal pockets $\geq 4 \mathrm{~mm}$ that combined PDT with SRP showing the reduction in number of probing depth at $76.24 \%$, which higher than control group which reduced to $75.24 \%$. This result may due to low-power laser encouraged in activate of increasing fibroblast that increased blood flow to promote in wound healing ${ }^{20)}$. However, the group of probing pocket depth $\geq 5 \mathrm{~mm}$ was compromised to manage by the non-surgical periodontal treatment only. Periodontal surgery is well advised to reduce the remaining periodontal pocket ${ }^{22}$. In this study, this test group had remaining number of probing pockets depth $\geq 5 \mathrm{~mm}$ only $18.65 \%$,

Table 5: Number of periodontal pockets $(\mathrm{n}) \geq 4 \mathrm{~mm}$ and $\geq 5 \mathrm{~mm}$ at different time intervals of control and test groups

\begin{tabular}{|c|c|c|c|c|c|c|}
\hline $\begin{array}{l}\text { Number of } \\
\text { periodontal pockets } \\
\text { (n) }\end{array}$ & Baseline & 1 month (\%) & 3 months (\%) & 6 months (\%) & $\begin{array}{l}\text { Difference 0-6 } \\
\text { months }\end{array}$ & $\begin{array}{c}\text { Remaining } \\
\text { number of PD } \\
\text { (\%) }\end{array}$ \\
\hline \multicolumn{7}{|l|}{$\mathrm{n}$ pocket $\geq 4 \mathrm{~mm}$} \\
\hline Control group & 844 & $485(57.46) \mathrm{A}$ & 388 (45.97)A & 209 (24.76)A & $635(75.24)$ & 24.76 \\
\hline Test group & 839 & $513(61.14) \mathrm{A}$ & 383 (45.65)A & 197 (23.48)A & $642(76.52)$ & 23.48 \\
\hline$P$-value & - & 0.44 & 0.40 & 0.07 & & \\
\hline \multicolumn{7}{|l|}{$\mathrm{n}$ pocket $\geq 5 \mathrm{~mm}$} \\
\hline Control group & 430 & $251(58.37) \mathrm{A}$ & $171(36.77) \mathrm{A}$ & 87 (20.23)A & $343(79.77)$ & 20.23 \\
\hline Test group & 488 & $285(58.40) \mathrm{A}$ & 175 (35.86)A & 91 (18.65)A & $397(81.35)$ & 18.65 \\
\hline$P$-value & - & 0.99 & 0.22 & 0.54 & & \\
\hline
\end{tabular}

Different uppercase letters represent intragroup statistically significant difference (McNemar Test, $P<0.05$ ) 
compare to the baseline, which had less than control group at $20.23 \%$. Similarly study of Kolbe MF et al. ${ }^{21)}$ reported that at 6 months after treatment, test group had percentages of number with probing pocket depth $\geq 5$ $\mathrm{mm}$ at $14.28 \%$ which was less than control group at $19.04 \%$. Though, result of this study was not statistically significant difference, but the less remaining number of probing pockets depth $\geq 5 \mathrm{~mm}$ revealing the additional benefit treatment for non-surgical periodontal surgery, decreasing treatment time and increasing patient's comfort.

Previous studies have compared the use of PDT with antimicrobial drug mostly in patients diagnosed with aggressive periodontitis. Arweiler NB et al. ${ }^{23)}$ compared the use of antimicrobial drug with PDT, and found that the received PDT group and the received antimicrobials drug group leading to statistically significant clinical improvements comparing with baseline. Still, PDT cannot be recommended as a replacement of systemic antibiotics in these patients. Although antimicrobial drug might provide better clinical improvements than PDT, but antimicrobials should also be concern with their side effect, along with the higher risk of drug resistance in bacteria. However, there was very low risk of bacterial resistance in using PDT.

\section{Reference}

1: Cobb CM (1996): Non-surgical pocket therapy: Mechanical. Annals of Periodontology, 1:443-490.

2: Lindhe J, Westfelt E, Nyman S, Socransky SS, Haffajee AD (1984): Long-term effect of surgical/non-surgical treatment of periodontal disease. Journal of Clinical Periodontology, 11:448-458

3: Badersten A, Nilve'us R, Egelberg J (1981): Effect of nonsurgical periodontal therapy. I. Moderately advanced periodontitis. Journal of Clinical Periodontology, 8:57-72.

4: Ramfjord Sp, Caffesse RG, Morrison EC, Hill RW, Kerry GJ, Appleberry EA, et al (1987): 4 modalities of periodontal treatment compared over 5 years. Journal of Clinical Periodontology, 14:445-452.

5: Drisko CL, Cochran DL, Blieden T, Bouwsma OJ, Cohen RE, Damoulis P, et al. (2000): Position paper: sonic and ultrasonic scalers in periodontics. Research, Science and Therapy Committee of the American Academy of Periodontology. Journal of Periodontology, 71:1792-1801.

6: Adriaens PA, Adriaens LM (2004): Effects of nonsurgical periodontal therapy on hard and soft tissues. Periodontology 2000, 36:121-145.

7: Takasaki AA, Aoki A, Mizutani K, Schwarz F, Sculean A, Wang CY, et al. (2009): Application of antimicrobial photodynamic therapy in periodontal and peri-implant diseases. Periodontology 2000, 51:109-140.

8: Dobson J, Wilson M (1992): Sensitization of oral bacteria in biofilms to killing by light from a low-power laser. Archives of Oral Biology, 37:883-887.

9: Sarkar S, Wilson M (1993): Lethal photosensitization of bacteria in subgingival plaque from patients with chronic periodontitis. Journal of Periodontal Research, 28:204-210.
The vary results from several studies may cause from the differentiated in method regarding periodontal diagnosis, study design, type and concentration of photosensitizer, laser type, and exposure durations. Thus, the objective of this study was to compare the SRP alone with a single application of PDT combined SRP, and it showed significant reductions of gingival bleeding index, but not in additional improvement in pocket depth reduction and gain of clinical attachment after 6 months. Lulic $\mathrm{M}$ et al. ${ }^{24)}$ demonstrated that repeated PDT applications ( 5 times in 2 weeks) adjunctive to SRP significantly improved the probing pocket depth, clinical attachment level and bleeding on probing after 6 months compared with the group treated with SRP alone. Therefore, difference of method in studies may have contributed for the appearance of different results.

In conclusion, the present study showed that addition of a single application of PDT as an adjunctive therapy to SRP failed to result in an improvement in terms of probing pocket depth reduction, plaque index reduction and clinical attachment gain, but it resulted in a significantly greater reduction in gingival bleeding and gingival inflammation.

10: Soukos NS, Mulholland SE, Socransky SS, Doukas AG (2003): Photodestruction of human dental plaque bacteria: enhancement of the photodynamic effect by photomechanical waves in an oral biofilm model. Lasers in Surgery and Medicine, 33:161-168.

11: Komerik N, Wilson M, Poole S (2000): The effect of photodynamic action on two virulence factors of gram-negative bacteria. Photochemistry and Photobiololy, 72:676-680.

12: Sigusch BW, Pfitzner A, Albrecht V, Glockmann E (2005): Efficacy of photodynamic therapy on inflammatory signs and two selected periodontopathogenic species in a beagle dog model. Journal of Periodontology, 76:1100-1105.

13: Komerik N, Nakanishi H, MacRobert AJ, Henderson B, Speight P, Wilson M (2003): In vivo killing of Porphyromonas gingivalis by toluidine blue-mediated photosensitization in an animal model. Antimicrobial Agents Chemotherapy, 47:932- 940 .

14: Andersen R, Loebel N, Hammond D, Wilson M (2007): Treatment of periodontal disease by photodisinfection compared to scaling and root planing. The Journal of Clinical Dentistry, 18: 34-38.

15: Braun A, Dehn C, Krause F, Jepsen S (2008): Short-term clinical effects of adjunctive antimicrobial photodynamic therapy in periodontal treatment: a randomized clinical trial. Journal of Clinical Periodontology, 35:877-884.

16: Chondros P, Nikolidakis D, Christodoulides N, Rossler R, Gutknecht N, Sculean A (2009): Photodynamic therapy as adjunct to non-surgical periodontal treatment in patients on periodontal maintenance: a randomized controlled clinical trial. Lasers in Medical Science, 24:681- 688.

17: Christodoulides N, Nikolidakis D, Chondros P, Becker J, 
Schwarz F, Rossler R, et al (2008): Photodynamic therapy as an adjunct to non-surgical peridoontal treatment: a randomized controlled clinical trial. Journal of Periodontology, 79:1638-1644

18: Polansky R, Haas M, Heschl A, Wimmer G (2009): Clinical effectiveness of photodynamic therapy in the treatment of periodontitis. Journal of Clinical Periodontology, 36: 575580.

19: Raghavendva M, Koregol A, Bhola S (2009): Photodynamic therapy: a targeted therapy in periodontics. Australien Dental Journal, 54 Suppl 1:S102-109.

20: Qadri T, Miranda L, Tuner J, Gustafsson A (2005): The shortterm effects of low-level lasers asadjunct therapy in the treatment of periodontal inflammation. Journal of Clinical Periodontology, 32:714-719.

21: Kolbe MF, Ribeiro FV, Luchesi VH, Casarin RC, Sallum EA, Nociti FH Jr, et al (2014): Photodynamic therapy during supportive periodontal care: clinical, microbiologic, immunoin- flammatory, and patient-centered performance in a splitmouth randomized clinical trial. Journal of Periodontology, 85:277-286.

22: Kaldahl WB, Kalkwarf KL, Patil KD, Molvar MP, Dyer JK (1996): Long-term evaluation of periodontal therapy: I. Response to 4 therapeutic modalities. Journal of Periodontology, 67:93-102.

23: Arweiler NB, Pietruska M, Skurska A, Dolinska E, Pietruski JK, Bläs M, et al (2013): Nonsurgical treatment of aggressive periodontitis with photodynamic therapy or systemic antibiotics. Three-month results of a randomized, prospective, controlled clinical study. Schweiz Monatsschr Zahnmed, 123:532-544.

24: Lulic M, Leiggener GI, Salvi GE, Ramseies CA, Mattheos N, Lang NP (2009): One-year outcomes of repeated adjunctive photodynamic therapy during periodontal maintenance: a proof-of-principle randomized-controlled clinical trial. Journal of Clinical Periodontology, 36:661-666.

\section{Conflict of interest:}

The authors declare that they have no conflict of interest.

\section{Acknowledgement:}

This study was supported by Research Fund of Srinakharinwirot University. 